\title{
The inhibitory activity on the rate of prostaglandin production by Zingiber officinale var. Rubrum
}

\author{
Fauzan Fikri ${ }^{1}$, Nyi Mekar Saptarini ${ }^{1}$, Jutti Levita ${ }^{2}$ \\ ${ }^{1}$ Department of Pharmaceutical Analysis and Medicinal Chemistry, Faculty of Pharmacy, Universitas \\ Padjadjaran, Jatinangor, West Java, Indonesia. \\ ${ }^{2}$ Department of Pharmacology and Clinical Pharmacy, Faculty of Pharmacy, Universitas Padjadjaran, \\ Jatinangor, West Java, Indonesia.
}

\begin{abstract}
Red ginger (Zingiber officinale var. Rubrum) is widely used by Indonesian as a traditional medicine to treat inflammation. The aim of this research was to provide information regarding the inhibitory activity of red ginger rhizome infusion on the rate of prostaglandin production. The red ginger rhizome used in this research was collected from Manoko plantation, Lembang. This research was conducted by Colorimetric COX Inhibitor Screening Assay method using TMPD (N,N,N',N'-tetramethyl-p-phenylendiamine) as reagent. Phytochemical screening showed that flavonoid, quinone, and monoterpenoid/sesquiterpenoid were detected in both dried herbs and water extract. Three spots were detected on thin-layer chromatography system with a mobile phase of chloroform:methanol (5:5). The rate of prostaglandin formations either by red ginger rhizome infusion or acetylsalicylic acid on COX-1 is slower (at $25^{\text {th }}$ minutes) rather than COX-2 (5th minutes). The strength of cyclooxygenase by red ginger rhizome infusion is weaker than acetosal.
\end{abstract}

Keywords: acetosal, antiinflammation, cyclooxygenase, NSAIDs, red ginger.

\section{Introduction}

Inflammation is a normal protective response to tissue injury caused by physical trauma, microbial toxin, or harmful chemicals. Inflammation is caused by the release of chemical mediators (histamine, prostaglandins) from damaged tissue. ${ }^{1}$ Symptoms of inflammatory processes include heat (calor), redness (rubor), swelling (tumor), and impaired function (function laesa). ${ }^{2}$ Statistical data shows that the prevalence of inflammation is quite prevalent, for example, inflammation of gastrointestinal inflammation bowel disease (IBD) reaches 396 out of 100,000 cases $^{3}$.
The cases of gout arthritis occurred as much as $45.9 \%$ of the 100,000 cases with the most sufferers were men. ${ }^{4}$

The most common target of inflammatory treatment is inhibiting prostaglandin formation as a major inflammatory mediator. This mediator is produced from arachidonic acid through a cyclooxygenase (COX) pathway involving COX enzymes in the production of prostaglandins. ${ }^{5} \mathrm{COX}$ serves as a catalyst in the first stage of the biosynthesis process of prostaglandins, thromboxane, and prostacyclin. There are two forms of COX-2 isoform

Corresponding author: Fauzan Fikri, Department of Pharmaceutical Analysis and Medicinal Chemistry, Faculty of Pharmacy, Universitas Padjadjaran, Jatinangor, West Java, Indonesia.

Email:justojansiregar@gmail.com 
enzymes, namely COX-1 and COX-2. COX1 is found in many tissues and is responsible for maintaining normal body function including gastric mucosal integrity. Meanwhile, COX-2 was not found in tissues under normal conditions, but was induced by various stimuli associated with prostaglandin production during inflammatory, pain, and pyretic. ${ }^{6,7}$ The prostaglandin formation can be inhibited by nonsteroidal antiinflammatory drugs (AINS) and COX enzyme-specific inhibitors. NSAIDs work by inhibiting COX enzymes so that the conversion of arachidonic acid into prostaglandins is impaired. The effects of NSAID therapy may cause gastrointestinal side effects with inhibitory mechanisms on COX-1 enzymes and side effects on the cardiovascular system with COX-2 enzyme inhibition mechanism..$^{8-10}$.

Plants can be a source of anti-inflammatory drugs. Group of secondary metabolite compounds that have antiinflammatory activity through inhibition of COX enzymes are terpenoid groups, flavonoids and phenolates ${ }^{11,12}$. The development of drugs from natural resource is expected to be a source of new anti-inflammatory drugs with lower side effects. Zingiber officinale var. Rubrum (ginger red) is empirically used as anti-inflammatory. Red ginger contains essential oil (1-3\%), oleoresin, and protease. Red ginger oleoresin contains many active ingredients and most of them give a spicy flavor effect, including gingerol, shogaol, eugenol, myristic acid, paradol, zingiberen and zingeron. ${ }^{13}$ Its essential oil consists of monoterpenes such as geranial (sitral a) and neral (sitral b) and sesquiterpenes such as bisabolon, zingiberen, and sesquiterpene. ${ }^{13}$ Zingiberen compounds, bisabolon, gingerol, and shogaol are known to have anti-inflammatory activity and antiulcer. ${ }^{14}$

Phenolic compounds in red ginger such as gingerol have potential as anti-inflammatory with IC50 $5.5 \mu \mathrm{M}$ value on prostaglandin biosynthesis. ${ }^{15}$ The terpenoid group compounds such as zingiberen are known to inhibit significant gastric lesions ${ }^{16}$. The use of oral ginger water extract can reduce inflammation effectively but is weaker than indomethacin. ${ }^{17}$

The purpose of this study was to investigate the inhibition of COX enzyme by red ginger rhizome infusa. The COX-1 and COX-2 inhibition tests were carried out by colorimetric method using TMPD reagents $(\mathrm{N}, \mathrm{N}, \mathrm{N}$ ', $\mathrm{N}$ 'tetramethyl-p-phenylenediamine). COX-1 and COX-2 enzyme inhibitory activity can be seen from TMPD chromogenic changes that occur during PGG2 reduction to $\mathrm{PGH} 2 .{ }^{18}$

\section{Methods}

\section{Instruments}

The instruments used in this study were 96-wells plate (Cayman Chemical), freeze dryer (Telstar), UV 254 and $366 \mathrm{~nm}$ (Camag UV Betrachter) lamps, microplate reader (MRX TC revelation), water baths, eppendorf tubes, thermometers, analytical scales (Sartorius), tip micropipette tips, vortex mixer (VM-300), and glass equipments commonly used in laboratories.

\section{Materials}

Materials used int his study included distilled water, double distilled water (Ipha Laboratories), amyl alcohol (Great eternal tower), ammonia (Great eternal tower), $2 \mathrm{~N}$ hydrochloric acid (Great eternal tower), iron (III) chloride (Merck), 96\% ethanol (Merck), ether (Merck), ethyl acetate (Merck), gelatin (Merck), potassium hydroxide 5\%, Colorimetric COX inhibitor screening assay kit No. 701050 (Cayman Chemical), chloroform (Merck), Dragendorff reagent (bismuth (III) nitrate in $10 \mathrm{M}$ hydrochloric acid), LiebermannBurchard reagent (acetic acid anhydrous in concentrated sulfuric acid), Mayer reagents (mercury (II) chloride and potassium iodide 
in distilled water), vanillin reagents in sulfuric acid, red ginger rhizome, magnesium metal powder, and GF254 silica (Merck).

\section{Plants determination}

Samples of red ginger rhizome were obtained from Manoko plantation, Lembang-Bandung in fresh and simplicia form. Fresh form of simplicia was determined in the Laboratory of Taxonomic Department of Biology Faculty of Mathematics and Natural Sciences, Universitas Padjadjaran.

\section{Infundation}

A total of $100 \mathrm{~g}$ of simplicia red ginger rhizome extracted in $1 \mathrm{~L}$ of water for 15 minutes was calculated starting from $90^{\circ} \mathrm{C}$. After that the liquid infusa was freeze-dried by using a freeze dryer (Telstar) to obtain a dry extract. Dry extracts were stored in tightly sealed containers.

\section{Phytochemical screening}

Phytochemical screening was conducted to obtain the following class of compoundsgroup of alkaloid compounds, flavonoid compounds, polyphenol compounds, tannin compounds, monoterpenoid and sesquiterpenoid compounds, triterpenoid and steroid compounds, quinone compound, and saponin compounds.

Thin layer chromatography (TLC) optimization

A total of $20 \mu \mathrm{L}$ of extract dissolved with $96 \%$ ethanol was bottled on the starting line ( $1 \mathrm{~cm}$ distance from the edge) of the GF254 silica plate measuring $10 \mathrm{~cm} \times 1 \mathrm{~cm}$ using a capillary pipe. The plate was left for a while until the solvent evaporates. The TLC plates were eluted using a solution of the developer in a pollutant vessel that has been saturated to the finish line. The resulting spots were then observed in visible light, under UV light 254 $\mathrm{nm}$ and $366 \mathrm{~nm}$, and using vanilin-sulphate spotting pencils. The values of $\mathrm{Rf}$ and Rs of each spots were then calculated.

\section{Sample preparation}

Stock solution was made with concentration $5 \mathrm{mg} / \mathrm{ml}$ by $50 \mathrm{mg}$ sample dissolved in $10 \mathrm{ml}$ ethanol $96 \%$ and made by stratified dilution so that got four other concentration variation that is $2.5 \mathrm{mg} / \mathrm{ml}, 1,25 \mathrm{mg} / \mathrm{ml}, 0.625 \mathrm{mg} / \mathrm{ml}$

Table 1. TLC extract optimization result

\begin{tabular}{lcccccc}
\hline & & & \multicolumn{3}{c}{ Colour detection } & Colour \\
\cline { 6 - 7 } \multicolumn{1}{c}{ Mobile phase } & $\begin{array}{c}\text { Spots } \\
\text { Number }\end{array}$ & Rf & UV & UV & Vanilin & $\begin{array}{c}\text { detection } \\
\text { Vanilin } \\
\text { Sulphate }\end{array}$ \\
\hline Methanol : Water (5:5) & 1 & 0.325 & - & - & Purple & Yellow \\
& 2 & 0.8125 & - & - & Purple & Yellow \\
Chloroform : Methanol (2:8) & 1 & 0.7125 & - & Green & Purple & - \\
Chloroform : Methanol (5:5) & 1 & 0.125 & Black & - & Purple & Yellow \\
& 2 & 0.275 & Black & - & Purple & Yellow \\
Chloroform : Methanol (7:3) & 3 & 0.65 & Black & Green & Purple & - \\
& 1 & 0.1000 & Black & Green & Purple & - \\
Chloroform : Methanol (8:2) & 2 & 0.8750 & - & - & Purple & Yellow \\
& 1 & 0.1250 & Black & - & Purple & Yellow \\
\hline Ethyl Acetate & 2 & 0.7500 & - & - & Purple & - \\
\hline
\end{tabular}


and $0.3125 \mathrm{mg} / \mathrm{ml}$.

Preparation of reagents Cayman COX Inhibitor Assay Kit No. 701050

1. Test buffer (10X) (Item No. 760114). A total of $3 \mathrm{~mL}$ of concentrated test was dissolved with $27 \mathrm{~mL}$ of double distilled water. This final test buffer contained Tris- $\mathrm{HCl} 0.1 \mathrm{M}$ with a $\mathrm{pH}$ of 8 . This buffer was used to dissolve heme and COX enzymes. Stable for two weeks at $4^{\circ} \mathrm{C}$.

2. Heme (Item No. 760116) vial contained a heme solution in dimethylsulphooxide (DMSO). A total of $88 \mu \mathrm{L}$ heme was dissolved with $1.912 \mathrm{ml}$ of a liquid test
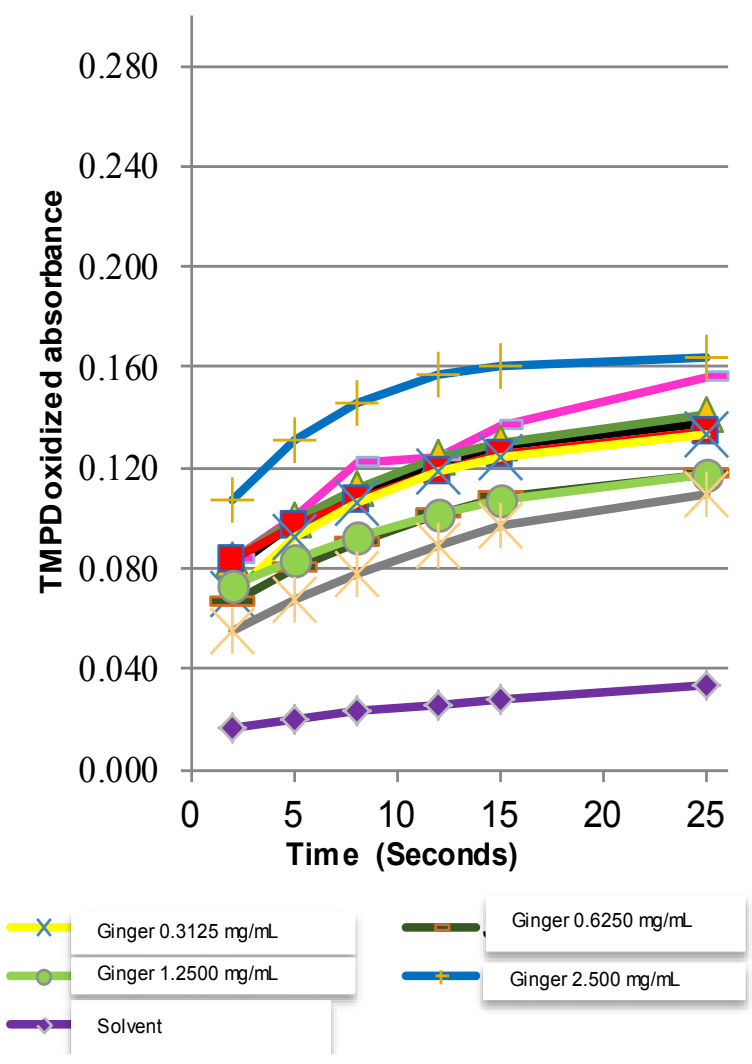

before used. Stable for 12 hours at room temperature.

3. Colorimetric COX Assay COX-1 (ovine) (Item No. 760110). A $200 \mu \mathrm{l} \mathrm{COX-1} \mathrm{en-}$ zyme was dissolved with $400 \mu \mathrm{l}$ of liquid test buffer and stored in ice. This diluted enzyme was stable for 1 hour.

4. Colorimetric COX Assay COX-2 (human) (Item No. 760119). A total of $150 \mu 1$ COX-2 enzyme was dissolved with 450 $\mu l$ of liquid test buffer and stored in ice. This diluted enzyme is stable for 1 hour.

5. Arachidonic Acid (Item No. 760113) vial contained an arachidonic acid solution

Figure 1. The TMPD kinetics curve

Information :

1. SD (a) $= \pm 0.0219, \mathrm{SD}(\mathrm{b})= \pm 0.03707 ; \mathrm{n}=3$

2. The solvent contained test buffer, heme, ethanol, arachidonic acid and TMPD

3. Negative control contained test buffer, heme, ethanol, COX enzyme, arachidonic acid and TMPD 
in ethanol. A $100 \mu \mathrm{l}$ substrate was transferred to another vial, added $100 \mu \mathrm{L} \mathrm{KOH}$ (Item No. 760115), vortex, and dissolved with $1.8 \mathrm{ml}$ of double distilled water to obtain a final concentration of $1.1 \mathrm{mM}$. This arachidonic acid solution should be used in 30 minutes.

6. $\mathrm{KOH}$ (Pottasium Hydroxide) (Item No. 760115). This vial contained $0.1 \mathrm{M} \mathrm{KOH}$ and was ready for use

7. TMPD substrate (Item No. 760117). This vial contained a TMPD solution (tetramethyl-p-phenylenediamine) and wasready for use

Implementation of antiinflammatory activity test with Cayman COX Inhibitor assay kit no. 701050

1. Background Wells (BW) total of $160 \mu \mathrm{L}$ test buffer and $10 \mu \mathrm{L}$ heme were put into three wells.

2. $100 \%$ Initial Activity Wells (A). A total of $150 \mu \mathrm{L}$ test buffer, $10 \mu \mathrm{L}$ heme, and $7 \mu \mathrm{L}$ enzyme (COX-1 or COX-2) were put into three wells.

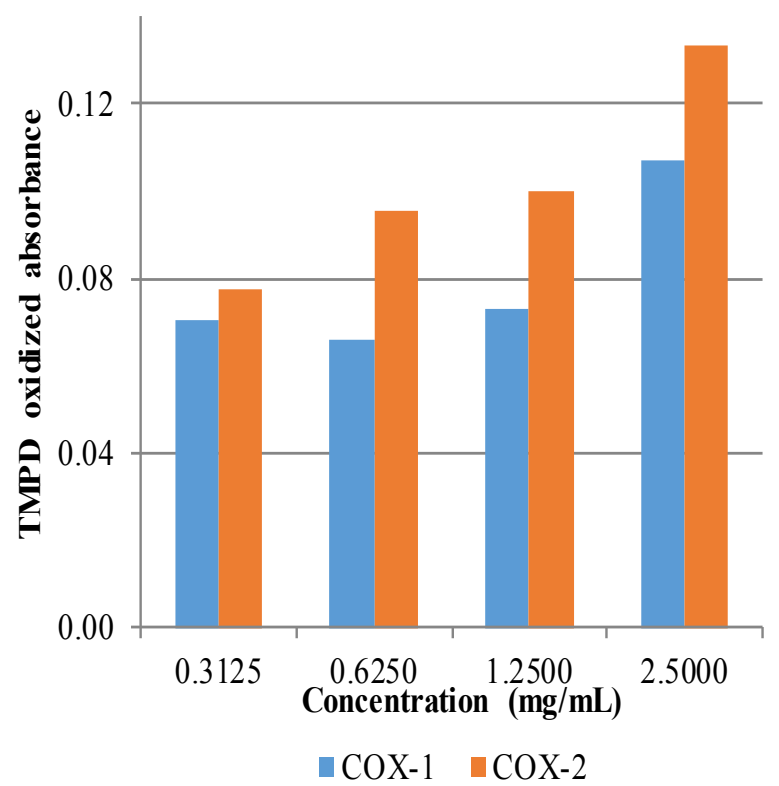

3. Inhibitor Wells. A total of $150 \mu \mathrm{L}$ test buffer, $10 \mu \mathrm{L}$ heme, and $7 \mu \mathrm{L}$ enzyme (COX1 or COX-2) were put into three wells.

4. Added $20 \mu \mathrm{L}$ inhibitor to wells inhibitor and $20 \mu \mathrm{L}$ solvent ( $96 \%$ ethanol) to $100 \%$ initial activity well and background well.

5. Plate was shaken gently for few seconds and incubated for 5 minutes at $25^{\circ} \mathrm{C}$.

6. Then, all of the wells used were added 15 $\mu \mathrm{L}$ substrate solution of TMPD

7. All of the wells used were added $20 \mu \mathrm{L}$ arachidonic acid immediately.

8. Plate was shaken carefully for a few seconds and incubated for 2 minutes at $25^{\circ} \mathrm{C}$.

9. Then, the absorbance was measured at a wavelength of $590 \mathrm{~nm}$.

\section{Data analysis}

The average value of absorbance for all samples were calculated and converted into a graph between absorbance of time variation and absorbance histogram to concentration.

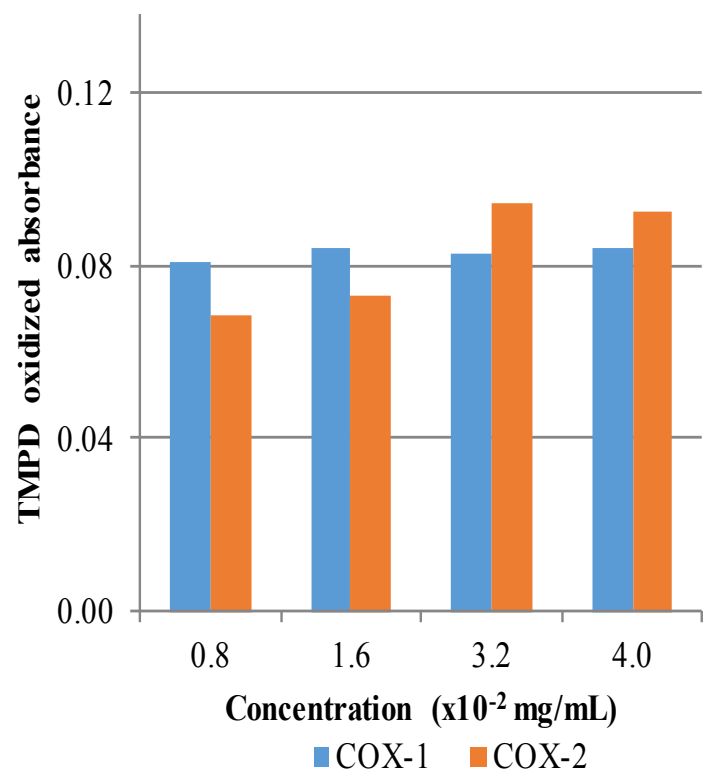

Figure 2: Histogram inhibition of COX enzyme by red ginger rhizome infusion (a) and acetosal (b) 


\section{Results And Discussion}

\section{Plant determination result}

The plant determination result showed that the plants used were red ginger rhizome (Zingiber officinale var Rubrum) which was a plant of Zingiberaceae family.

\section{Infundation result}

100 grams of red ginger simplicia heated in $1 \mathrm{~L}$ of water for 15 minutes was calculated starting from a temperature of $90^{\circ} \mathrm{C}$. After that liquid infusa was freeze-dried with freeze dryer (Telstar) to obtain 8.78 grams of dry extract with yield of $8.78 \%$.

\section{Phytochemical screening}

The results of phytochemical screening of simplicia and extracts showed the presence of secondary metabolites of flavonoid, quinone, monoterpenes and sesquiterpenes so that the extraction process by infundation method did not destroy or eliminate the secondary metabolite component present in the simplicia.

\section{TLC optimization}

The TLC profile of a plant extract showed an early description of the chemical composition of the plant extract. Optimization of TLC extract was carried out by using GF254 silica gel plates as a stationary phase and a mixture of varying developer solutions as a mobile phase with the spotting agent, ie vanillinsulphate. The protective effects of vanillinsulphate solution were used to identify and confirm the polyphenolic, monoterpenoid and sesquiterpenoid chemical compounds. After the development process was done, the TLC plates were observed visually, using UV light 254 and $366 \mathrm{~nm}$, as well as by using the spotting viewer. The TLC results can be seen in the Table 1.

The mobile phase of chloroform : methanol (5:5) gave three distinctly spots, measured from Rs (resolution) greater than 1. There were 2 values of Rs (between spots 1-2 and spots 2-3) of 1.78 and 4.91 on the TLC plate. The mobile phase used were chloroform is semipolar (with polarity index 4,1) while methanol was polar (with polarity index 5,1 ). The addition of the spotting agent of vanilinsulphate solution gave purple color to the spots indicating the presence of monoterpenoid/ sesquiterpenoid group compounds. The secondary metabolites contained in the extracts that were suspected to give antiinflammatory activity were semipolar terpenoid groups because the developer of chloroform:methanol (5:5) was able to provide a better separation pattern compared to other mobile phase solutions.

\section{COX Enzyme Inhibition}

Antiinflammatory activity of red ginger rhizome extract on COX enzyme was analyzed based on the approach of using red ginger rhizome empirically by the society to treat inflammation. There are three classes of secondary metabolites that have anti-inflammatory effects by inhibition of COX enzymes, terpenoids, flavonoids and phenolates. ${ }^{19}$ The presence of terpenoids and flavonoids in the red ginger rhizome is thought to overcome inflammation through inhibition of COX enzymes.

The COX inhibition test was performed in vitro using a Colorimetric COX Inhibitor Screening Assay kit. 701050 from Cayman Chemical Company. In this kit Tris-HCl buffer retained enzyme stability, heme as enzyme cofactor, COX-1 and COX-2 enzymes, arachidonic acid as enzyme substrate, $\mathrm{KOH}$, and TMPD (N, N, N ', N'- tetramethyl-p -phenyliamediamine) as a colorimetric substrate. TMPD served as an indicator or compound marker of COX enzyme activity. ${ }^{20}$

The principle of this enzyme kit is the TMPD oxidation reaction due to heme peroxidase 
activity, so TMPD releases one electron to form a colored compound which absorbs at $\lambda 590 \mathrm{~nm} .{ }^{21}$ The TMPD oxidation reaction is equivalent to the $\mathrm{PGG} 2$ reduction reaction to PGH2 by the activity of the COX enzyme. The higher the activity of the COX enzyme against the arachidonic acid substrate, the more TMPD is oxidized so that the higher the absorbance value. If the inhibitory activity of extracts on large COX enzymes, then the reduction of $\mathrm{PGG} 2$ to $\mathrm{PGH} 2$ will decrease, resulting in fewer oxidized TMPDs or lower absorbance values. In enzyme-catalyzed reactions, the arachidonic acid substrate occupies the active side of the COX enzyme forming a complex of temporary enzymes where this complex will loose again resulting in free COX enzymes and prostaglandin products. The reaction of the complex formation of these enzymes is reversible. As the reaction progresses, over time, the enzyme will be occupied entirely by the arachidonic acid substrate so that the resulting prostaglandin product will remain relatively constant over a period of time.

The results of the COX enzyme inhibition assay can be seen in Figure 1. Based on the results of testing of both COX enzymes, the measured TMPD absorbance increases with time. This indicates that the amount of oxidized TMPD was increasing as the product of prostaglandins produced from COX enzymes and arachidonic acid substrate increases. In Figure 1 (a), increased absorbance of oxidized TMPD or prostaglandin formation in COX-1 was relatively slower than the formation of prostaglandins in COX-2. This means that in COX-1, the red ginger rhizome infusion had a higher affinity with the enzyme, so the arachidonic acid slowly reacts with the enzyme (in the test procedure, arachidonic acid and TMPD was added last after incubation of the enzyme with infusa for $5 \mathrm{~min}$ ). Figure 1 (b) in the time span of 2 to 12 minutes the ab- sorbance value of oxidized TMPD or measurable prostaglandin formation increases rapidly, while in the 12 to 25 minute period the absorbance value is relatively constant. This is because the arachidonic acid substrate has reacted entirely to the COX-2 enzymes so that the product of the oxidized prostaglandin or absorbance TMPD is relatively constant. This also applies to acetosal where the rate of prostaglandin formation in $\mathrm{COX}-1$ is slower than $\mathrm{COX}-2$.

In Figure 2 it can be seen that the inhibitory power of red ginger rhizome infusion in COX-1 and COX-2 is weaker than acetosal. This is evident from the large concentrations of red ginger rhizome infusion required to provide an almost equivalent inhibition with acetosal. In COX-1, an acetosal concentration of $3.2 \times 10^{-2} \mathrm{mg} / \mathrm{ml}$ gave an absorbance of 0.083 while red ginger rhizome infusion requires a concentration of $1.25 \mathrm{mg} / \mathrm{ml}$ to give an absorbance of 0.073 . In COX-2, acetosal with concentration $0.8 \times 10-2 \mathrm{mg} / \mathrm{ml}$ gave absorbance 0.068 wherein red ginger rhizome infusion requires concentration of 0.3125 $\mathrm{mg} / \mathrm{ml}$ to give absorbance of 0.0777 .

\section{Conclusions}

The rate of prostaglandin formation by red and acetic ginger rhizome infusion in COX-1 was slower than COX-2. Inhibitory strength of red ginger rhizome infusion in $\mathrm{COX}-1$ and COX-2 is weaker than acetosal.

\section{Acknowledgement}

None declared.

\section{Funding}

The study was not funded by any source of grants.

\section{Conflict of Interest}

The authors declared no potential conflicts of interest with respect to the research, 
authorship, and/or publication of this article.

\section{References}

1. Hunter P. The inflammation theory of disease: the growing realization that chronic inflammation is crucial in many diseases opens new avenues for treatment. EMBO Reports. 2012;13(11):968-970.

2. Beg S, Swain S, Hasan H, Barkat MA, Hussain MS. Systematic review of herbals as potential anti-inflammatory agents: recent advances, current clinical status and future perspectives. Pharmacognosy Reviews. 2011;5(10):120-137.

3. Lakatos, P.L. 2006. Recent trends in the epidemiology of inflammatory bowel diseases: up or down?. World Journal of Gastrointestinal. 12 (38): 6102-08.

4. Singh JA. Racial and gender disparities in patients with gout. Current rheumatology reports. 2013;15(2):307.

5. Ricciotti E, FitzGerald GA. Prostaglandins and inflammation. Arteriosclerosis, thrombosis, and vascular biology. 2011;31(5):986-1000.

6. Suleyman H, Demircan B, Karaguz Y. Anti-inflammatory and side effects of cyclooxygenase inhibitors. Pharmacology Reports. 2007;59(3):247-58.

7. Grosch S, Maier TJ, Schiffmann S, Geisslinger G. Cyclooxygenase-2 (COX-2)-independent anticarcinogenic effects of selective COX-2 inhibitors. Journal of The National Cancer Institute. 2006;98(11):736-47.

8. Rao PNP, Knaus EE. Evolution of nonsteroidal anti-inflammatory drugs (NSAIDs): Cyclooxygenase (COX) inhibition and beyond. Journal Pharmacy of Pharmaceutical Sciences. 2008;11(2):81s-110s.

9. Ziltener JL, Leal S, Fournier PE. Non-steroidal antiinflammatory drugs for athletes: an update. Annals of Physical and Rehabilitation Medicine. 2010;53(4):278-288.

10. Martin JE, Young GP, Leu RKL, and Hu
Y. Comparing the effects of $\mathrm{COX}$ and non-COX-inhibiting NSAIDs on enhancement of apoptosis and inhibition of aberrant crypt foci formation in rat colorectal cancer model. Anticancer Research. 2013;33(9):3581-3588.

11. Thoppil RJ, Bishayee A. Terpenoids as potential chemopreventive and therapeutic agents in liver cancer. World Journal of Hepatology. 2011;3(9):228-249.

12. Elsayed EA, El Enshasy H, Wadaan MAM, Aziz R. Mushrooms: A potential natural source of anti-inflammatory compounds for medical applications. Mediators of Inflammation. 2014;2014:805841.

13. Singh G, Kapoor IPS, Singh P, Heluani CS, Lampasona MP, and Catalan AN. Chemistry, antioxidant, and antimicrobial investigations on essentialoil and oleoresin of Zingiber officanale. Food and Chemical Toxicology. 2008;(46):32593302.

14. Anosike, C. A., Onyechi O., Lawrence U. S., Ezeanyika and Meshach M Nwuba. Anti-inflammatory and antiulcerogenic activity of the ethanol extract of ginger (Zingiber officinale). African Journal of Biochemistry Research. 2009;3(12):379384.

15. Wu, H. 2007. Isolation and Characterization of natural products from ginger and Allium ursinum [Accessed on: 6 Agustus 2014]. Available at: https://rucore.libraries.rutgers.edu/rutgers-lib/21295/

16. Zaghlool SS, Shehata BA, Abo-Seif AA, Abd El-Latif HA. Protective effects of ginger and marshmallow extracts on indomethacin-induced peptic ulcer in rats. Journal of Natural Science, Biology, and Medicine. 2015;6(2):421-428.

17. Mashhadi NS, Ghiasvand R, Askari G, Hariri M, Darvishi L, Mofid MR. Anti-oxidative and antiinflammatory effects of ginger in health and physical activity:review of current evidence. In- 
ternational Journal of Preventive Medicine. 2013;4(Suppl 1):S36-S42.

18. Kumar KA, Reddy TC, Reddy GV, Reddy DB, Mahipal SV. High-throughput screening assays for cyclooxygenase-2 and 5-lipoxygenase, the targets for inflammatory disorders. Indian Journal of Biochemistry and Biophysics. 2011;48(4): 256-261.

19. Jachak SM, Gautam R, Selvam C, Madhan $\mathrm{H}$, Srivastava. Anti-inflammatory, cyclooxygenase inhibitory and antioxidant activities of standardized extracts of Tridax procumbens L. Fitoterapia.
2010;82(2):173-177.

20. Mada SR, Metukuri MR, Burugula L, Reddanna P, Krishna DR. Antiinflammatory and antinociceptive activities of gossypin and procumbetin cyclooxygenase- 2 (COX-2) inhibition studies. Phytotherapy Research. 2009;23(6):878-84.

21. Cayman Chemical Company. 2014. Colorimetric $\mathrm{COX}$ inhibitor screening assay kit: item no. 701050. USA: Cayman Chemical Company. 